\title{
Dual Effect of Exogenous Nitric Oxide on Neuronal Excitability in Rat Substantia Gelatinosa Neurons
}

\author{
A-Reum Park, ${ }^{1}$ Hae In Lee, ${ }^{1}$ Dejidnorov Semjid, ${ }^{1}$ Do Kyung Kim, ${ }^{2}$ and Sang Woo Chun ${ }^{1}$ \\ ${ }^{1}$ Department of Oral Physiology, College of Dentistry, Institute of Wonkwang Biomaterial and Implant, Wonkwang University, \\ 344-2 Shinyong Dong, Iksan 570-749, Republic of Korea \\ ${ }^{2}$ Oral Biology Research Institute, Chosun University School of Dentistry, Gwangju 501-759, Republic of Korea \\ Correspondence should be addressed to Sang Woo Chun; physiol@wku.ac.kr
}

Received 19 September 2013; Revised 26 November 2013; Accepted 27 November 2013; Published 8 January 2014

Academic Editor: Dong-ho Youn

Copyright (C) 2014 A-Reum Park et al. This is an open access article distributed under the Creative Commons Attribution License, which permits unrestricted use, distribution, and reproduction in any medium, provided the original work is properly cited.

\begin{abstract}
Nitric oxide (NO) is an important signaling molecule involved in nociceptive transmission. It can induce analgesic and hyperalgesic effects in the central nervous system. In this study, patch-clamp recording was used to investigate the effect of NO on neuronal excitability in substantia gelatinosa (SG) neurons of the spinal cord. Different concentrations of sodium nitroprusside (SNP; NO donor) induced a dual effect on the excitability of neuronal membrane: $1 \mathrm{mM}$ of SNP evoked membrane hyperpolarization and an outward current, whereas $10 \mu \mathrm{M}$ induced depolarization of the membrane and an inward current. These effects were prevented by hemoglobin and 2-(4-carboxyphenyl)-4,4,5,5-tetramethylimidazoline-1-oxyl-3-oxide potassium salt (c-PTIO) (NO scavengers), phenyl $\mathrm{N}$-tert-butylnitrone (PBN; nonspecific reactive oxygen species scavenger), and through inhibition of soluble guanylyl cyclase (sGC). Pretreatment with n-ethylmaleimide (NEM; thiol-alkylating agent) also decreased effects of both $1 \mathrm{mM}$ and $10 \mu \mathrm{M}$ SNP, suggesting that these responses were mediated by direct S-nitrosylation. Charybdotoxin (CTX) and tetraethylammonium (TEA) (large-conductance $\mathrm{Ca}^{2+}$-activated $\mathrm{K}^{+}$channel blockers) and glybenclamide (ATP-sensitive $\mathrm{K}^{+}$channel blocker) decreased SNP-induced hyperpolarization. $\mathrm{La}^{3+}$ (nonspecific cation channel blocker), but not $\mathrm{Cs}^{+}$(hyperpolarization-activated $\mathrm{K}^{+}$channel blocker), blocked SNP-induced membrane depolarization. In conclusion, NO dually affects neuronal excitability in a concentrationdependent manner via modification of various $\mathrm{K}^{+}$channels.
\end{abstract}

\section{Introduction}

Nitric oxide (NO) is a pivotal signaling molecule involved in many diverse developmental and physiological processes in the mammalian nervous system [1-3]. NO is biosynthesized from L-arginine by specific neuronal and nonneuronal forms of NO synthase $[4,5]$. NO donors as well as endogenously produced NO play a role in many physiological processes, including smooth muscle relaxation, cellular proliferation, apoptosis, neurotransmitter release, and cell differentiation [6]. NO-induced effects are commonly mediated through the following processes: increased cGMP production upon activation of NO-sensitive soluble guanylyl cyclase (sGC), S-nitrosylation, tyrosine nitration, and NO interaction with superoxide $\left(\mathrm{O}_{2}{ }^{--}\right)$to form peroxynitrite $\left(\mathrm{ONOO}^{-}\right)[1,7,8]$.
Oxidative stress due to reactive oxygen species (ROS) such as $\mathrm{O}_{2}{ }^{--}$, hydrogen peroxide $\left(\mathrm{H}_{2} \mathrm{O}_{2}\right), \mathrm{NO}$, and $\mathrm{ONOO}^{-}$ interferes with normal cell function and can cause cell damage. Moreover, ROS is associated with chronic pain, particularly neuropathic and inflammatory pain $[9,10]$. NO has a dual role in the regulation of pain processes; it can mediate a nociceptive or induce an antinociceptive effect. Some studies suggest that spinal NO is involved in the potentiation of nociception. For example, it has been demonstrated that nerve injury- or tissue inflammation-induced mechanical hypersensitivity is reduced in nNOS knockout mice and by intrathecal administration of nNOS inhibitors [11-13]. Furthermore, NO, produced in the NOS-containing spinal cord neurons, plays a pivotal role in chronic pain $[14,15]$.

In contrast, other studies have shown that administration of NO donors can induce antinociceptive effects. For 
example, L-arginine and 3-morpholinosydnonimine (SIN-1; NO donor), administered intracerebroventricularly to mice, cause antinociception [16]. Intraplantar injection of sodium nitroprusside (SNP), a substance which nonenzymatically releases NO, also causes antinociception in rats [17].

The substantia gelatinosa (SG) of the dorsal horn is the first site of synaptic transmission in the nociceptive pathway, and it is an area vital for the integration and modulation of the peripheral nociceptive input. Understanding neuronal excitability in this area is fundamental to enhance our knowledge on nociceptive neurotransmission. However, despite many reports on the importance of $\mathrm{NO}$ in nociceptive processing in the spinal cord, the effect of $\mathrm{NO}$ on the excitability of spinal cord dorsal horn neurons remains unclear. In this study, the effect of different concentrations of $\mathrm{NO}$ on the membrane potential of SG neurons was investigated using patch-clamp recordings from transverse slices of the spinal cord.

\section{Materials and Methods}

2.1. Spinal Cord Slice Preparation. Sprague-Dawley rats (1418 days old) were first anesthetized with ether. The procedures were approved by the University of Wonkwang Committee on Ethics in the Care and Use of Laboratory Animals (WKU09076). Lumbosacral laminectomy was performed following intraperitoneal administration of $25 \%$ urethane. The spinal cord at spinal level L1-S3 was removed and placed in a preoxygenated solution at $1-2^{\circ} \mathrm{C}$. Transverse spinal slices, $350 \mu \mathrm{m}$ thick, were prepared using a vibroslicer (752M, Campden Instruments, Loughborough, UK) and incubated at $32^{\circ} \mathrm{C}$ for a recovery period of at least $1 \mathrm{~h}$. Afterwards, slices were transferred to a recording chamber mounted on a upright microscope.

2.2. Solution and Drugs. The dissecting solution for the spinal cord slice preparation was composed of (in $\mathrm{mM}$ ) 252 Sucrose, $2.5 \mathrm{KCl}, 0.1 \mathrm{CaCl}_{2}, 2 \mathrm{MgCl}_{2}, 10$ Glucose, $26 \mathrm{NaHCO}_{3}$, and $1.25 \mathrm{NaH}_{2} \mathrm{PO}_{4}$. The extracellular fluid used for the patch-clamp recording contained (in $\mathrm{mM}$ ) $117 \mathrm{NaCl}, 3.6 \mathrm{KCl}, 2.5 \mathrm{CaCl}_{2}, 1.2 \mathrm{MgCl}_{2}, 1.2 \mathrm{NaH}_{2} \mathrm{PO}_{4}, 25$ $\mathrm{NaHCO}_{3}$, and 11 glucose. It was continually aerated with $95 \%$ $\mathrm{O}_{2} / 5 \% \mathrm{CO}_{2}$, which kept the $\mathrm{pH}$ at approximately 7.4 . The pipette (internal) solution contained (in mM) $150 \mathrm{~K}-\mathrm{Glu}, 10$ Hepes, $5 \mathrm{KCl}$, 0.1 EGTA, $2 \mathrm{Mg}$-ATP, and $0.3 \mathrm{Na}$ GTP. The $\mathrm{pH}$ was adjusted to 7.3 by $\mathrm{KOH}$. $1 \mathrm{H}-[1,2,4]$ oxadiazole[4,3$\alpha$ ]quinoxaline-1-one (ODQ) and glibenclamide were dissolved in DMSO to prepare a stock solution. SNP, hemoglobin (Hb), 2-(4-carboxyphenyl)-4,4,5,5-tetramethylimidazoline1-oxyl-3-oxide potassium salt (c-PTIO), phenyl $N$-tertbutylnitrone (PBN), ODQ, lanthanum chloride, cesium chloride, charybdotoxin (CTX), tetraethylammonium (TEA), glibenclamide, apamin, and n-ethylmaleimide (NEM) were obtained from Sigma-Aldrich (St. Louis, MO, USA).

2.3. Patch-Clamp Recording. Microelectrodes were prepared from capillary glass tubes (TW150-3, WPI, USA) using a microelectrode pipette puller (PP830, Narishige, Japan).
Patch pipettes, filled with the pipette solutions, were used at a resistance ranging from 6 to $8 \mathrm{M} \Omega$. The substantia gelatinosa of the spinal cord was viewed with an upright microscope (BX50WI, Olympus, Japan). Membrane potential and current were recorded using an Axopatch 200B (Axon Instruments, USA) amplifier that was connected to a computer using an A/D converter (Digidata 1322A, Axon Instruments, USA). Membrane potential recording and data analyses were performed using pClamp software (Version 9.0, Axon Instruments, USA). Generated currents were filtered with a low-pass 8-pole Bessel filter at $2 \mathrm{kHz}$. All experiments were performed at room temperature $\left(22 \pm 1^{\circ} \mathrm{C}\right)$.

2.4. Fluorescence Imaging. For detection of nitric oxide, spinal cord slices were incubated with $10 \mu \mathrm{M}$ of 4 -amino5-methylamino-2,7-difluorofluorescein diacetate (DAF-FM DA) for 30 minutes at $32^{\circ} \mathrm{C}$. The slices were examined on an inverted fluorescence microscope (LSM 510, Carl Zeiss, Germany). Excitation wavelength was $488 \mathrm{~nm}$, and emission was measured at 515 to $565 \mathrm{~nm}$. A time series was used to record images every $30 \mathrm{~s}$.

2.5. Data Analysis. Differences in drug effects were analyzed using independent $t$-test and were considered significant when $P<0.05$. Data are expressed as mean \pm SEM.

\section{Results}

3.1. Effects of SNP $(1 \mathrm{mM}$ and $10 \mu \mathrm{M})$ on the Membrane Excitability in Substantia Gelatinosa Neurons of the Spinal Cord. During current-clamp recording, a high concentration of SNP $(1 \mathrm{mM})$ induced membrane hyperpolarization $(-7.5$ $\pm 1.0 \mathrm{mV}, n=62)$, whereas a low concentration $(10 \mu \mathrm{M})$ induced membrane depolarization $(4.4 \pm 0.7 \mathrm{mV}, n=32)$ (Figures 1(a) and 1(c)). When voltage clamp recording was performed at a holding potential of $-60 \mathrm{mV}$, SNP $(1 \mathrm{mM})$ induced an outward current $(5.7 \pm 0.6 \mathrm{pA}, n=50)$, whereas SNP $(10 \mu \mathrm{M})$ induced an inward current $(-4.8 \pm 1.1 \mathrm{pA}, n=$ 14) (Figures 1(b) and 1(d)). This suggests that SNP can elicit dual effects on the membrane excitability of SG neurons in a concentration-dependent manner.

\subsection{Effects of NO Scavengers on SNP-Induced Membrane} Potential Changes. We next investigated the effects of NO scavengers to determine whether the SNP-induced changes in membrane potential were due to the release of NO from the donor. SNP (1 mM)-induced hyperpolarization is significantly reduced in the presence of the NO scavengers, $\mathrm{Hb}(50 \mu \mathrm{M})(-4.5 \pm 0.9 \mathrm{mV}, n=8, P<0.05)$ and $\mathrm{c}-\mathrm{PTIO}$ $(200 \mu \mathrm{M})(-3.7 \pm 0.4 \mathrm{mV}, n=8, P<0.01)$ (Figures 2(a), 2(c), and $2(\mathrm{~g}))$. Furthermore, pretreatment with $\mathrm{Hb}(0.6 \pm 0.6 \mathrm{mV}$, $n=6, P<0.001)$ and $\mathrm{c}$-PTIO $(1.4 \pm 0.5 \mathrm{mV}, n=5, P<$ $0.01)$ significantly inhibited SNP $(10 \mu \mathrm{M})$-mediated depolarization (Figures 2(b), 2(d), and 2(g)). Pretreatment with PBN, the nonspecific ROS scavenger, significantly reduced SNPinduced hyperpolarization $(-2.2 \pm 1.6 \mathrm{mV}, n=5, P<0.05)$ (Figures 2(e) and 2(g)) as well as SNP-induced depolarization $(1.4 \pm 0.4 \mathrm{mV}, n=5, P<0.001)$ (Figures $2(\mathrm{f})$ and $2(\mathrm{~g}))$. These 


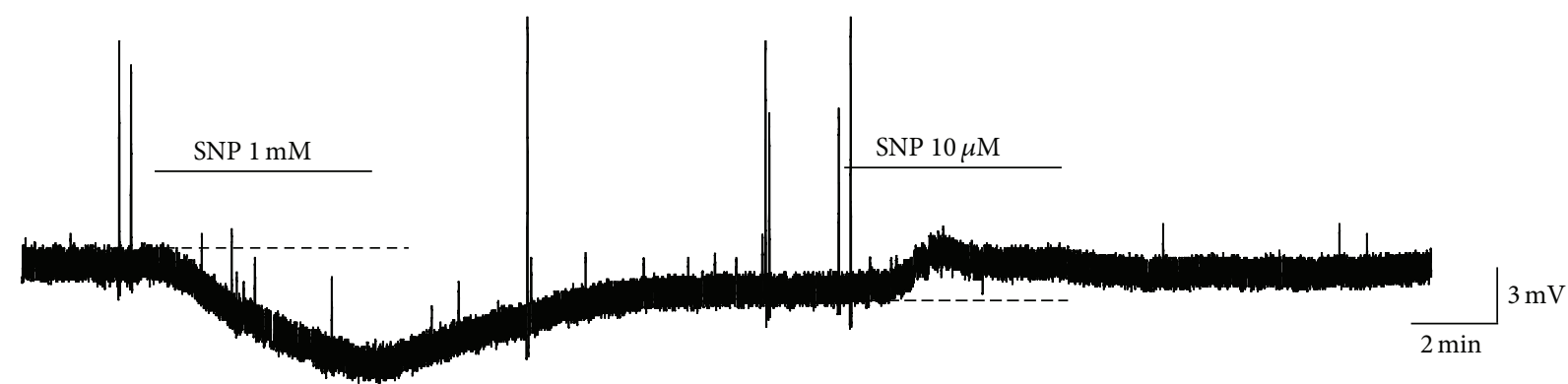

(a)

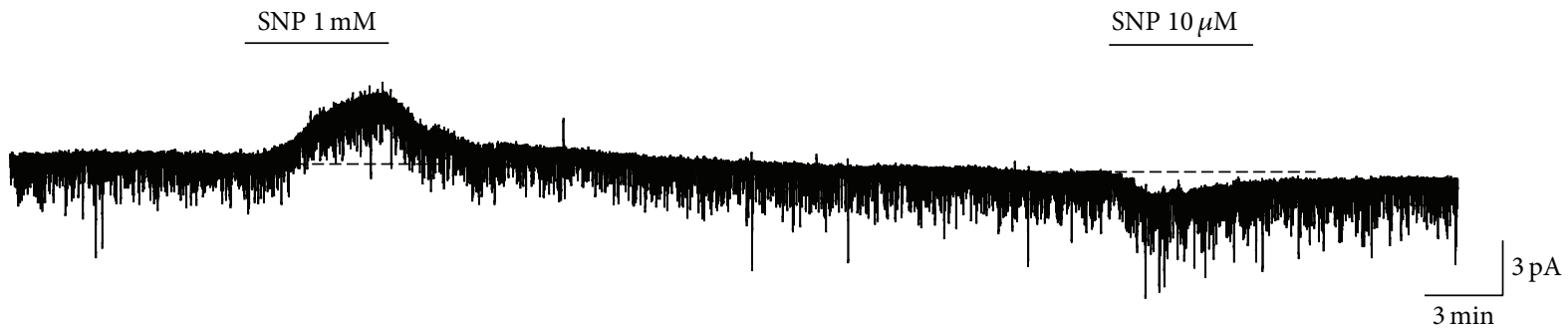

(b)

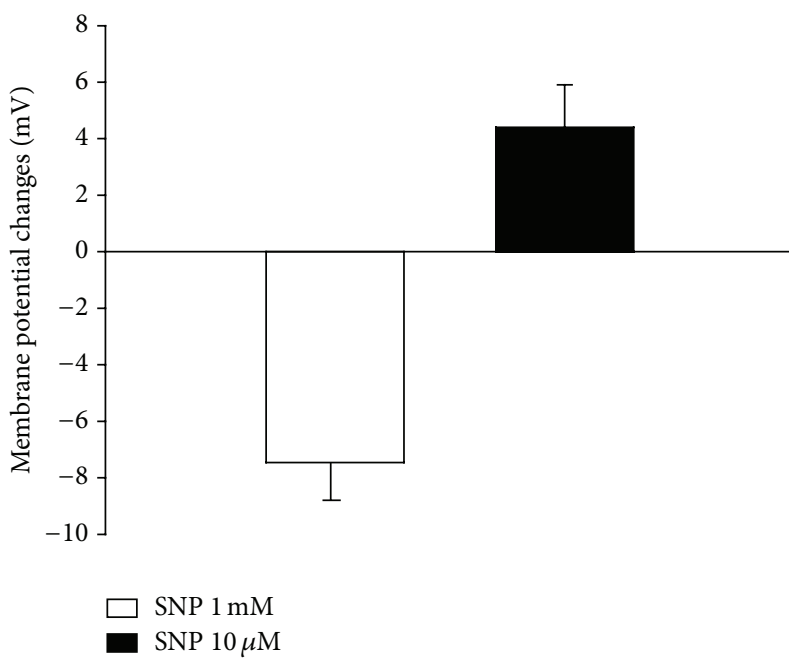

(c)

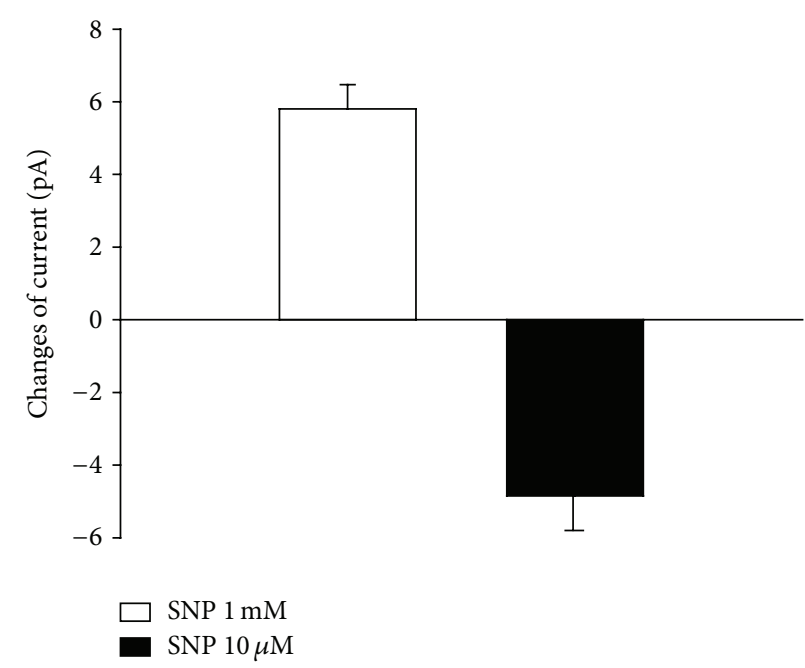

(d)

FIGURE 1: Effect of $1 \mathrm{mM}$ and $10 \mu \mathrm{M}$ SNP on the membrane excitability in substantia gelatinosa (SG) neurons of the spinal cord. (a) Currentclamp recording of membrane potentials of SG neurons showing the dual effect of SNP. SNP $(1 \mathrm{mM})$ induced membrane hyperpolarization, whereas SNP $(10 \mu \mathrm{M})$ elicited membrane depolarization. (b) Representative current traces of SG neurons recorded at a holding potential of $-60 \mathrm{mV}$. SNP $(1 \mathrm{mM})$ induced an outward current, whereas SNP $(10 \mu \mathrm{M})$ induced an inward current. (c) Bar graphs show the membrane potential changes evoked by different concentrations of SNP. (d) Bar graphs show the amplitude of current changes induced by different concentrations of SNP. Mean \pm SEM.

results suggest that NO is released by SNP, which in turn induces the changes in membrane excitability of SG neurons.

\subsection{Fluorescence Response of $N O$ in DAF-FM DA-Loaded} $S G$ Neurons. The effect of SNP on NO production was determined using the cell-permeable fluorescent probe, DAFFM DA. SNP is a donor of NO; thus, it can release $\mathrm{NO}$, which then reacts with DAF-FM to produce fluorescence. Figure 3 shows changes in intracellular fluorescence intensity over a time series of images taken every $30 \mathrm{~s}$. Intracellular NO production was induced during SNP perfusion for $5 \mathrm{~min}$.
Increased NO production $(128.0 \pm 6.1 \%, n=12)$ was inhibited by the NO scavenger, $\mathrm{Hb}(50 \mu \mathrm{M})(92.0 \pm 0.5 \%, n=5, P<$ 0.05 ) (Figures 3(a), 3(b), and 3(d)), and the ROS scavenger, PBN (2 mM) (95.1 $\pm 2.1 \%, n=7, P<0.05)$ (Figures 3(a), 3(c), and $3(\mathrm{e}))$.

3.4. Involvement of Soluble Guanylyl Cyclase in the SNPInduced Response. $\mathrm{NO}$ has been shown to activate sGC, leading to an increase in cGMP levels. Thus, to determine whether the effect of SNP was mediated by the activation of sGC, ODQ $(40 \mu \mathrm{M})$, a selective sGC inhibitor, was used 


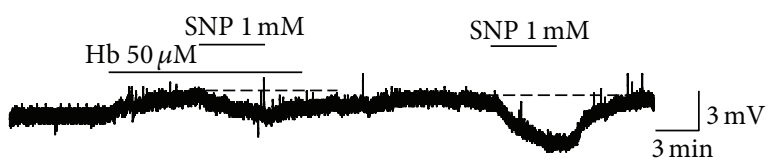

(a)

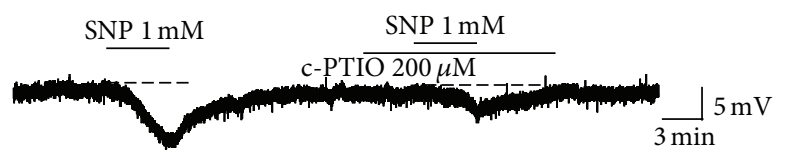

(c)

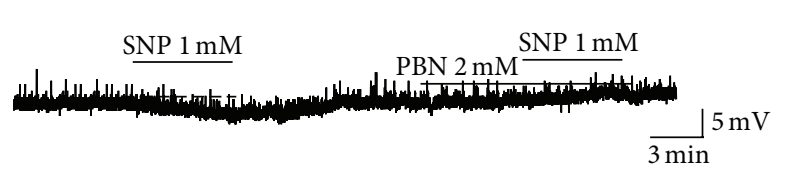

(e)

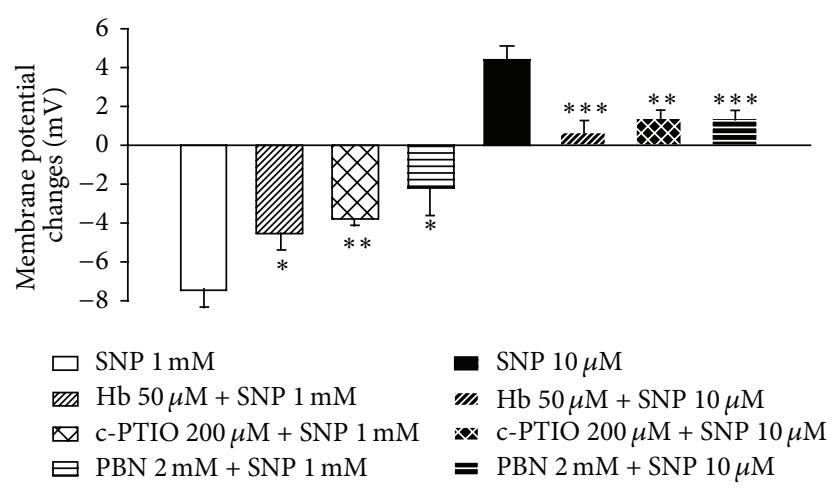

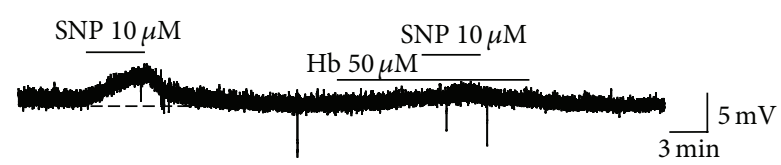

(b)

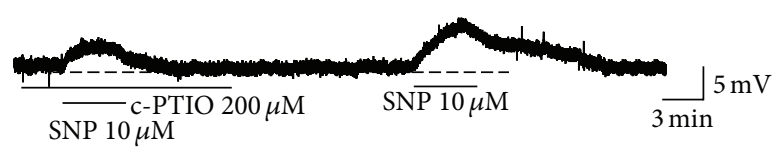

(d)

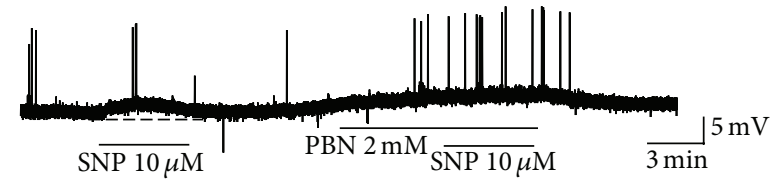

(f)

(g)

FIGURE 2: Effect of the NO scavengers on SNP-induced membrane potential changes. SNP (1 mM)-induced hyperpolarization was decreased by pretreatment with $\mathrm{Hb}$ (a) and c-PTIO (c). Hb (b) and c-PTIO (d) decreased SNP (10 $\mu \mathrm{M})$-induced depolarization. (e) Pretreatment with PBN inhibited SNP (1 mM)-induced hyperpolarization. (f) PBN reduced SNP (10 $\mu \mathrm{M})$-induced depolarization. (g) Summary of data obtained under the control condition of SNP-induced responses and pretreatment with Hb, c-PTIO, and PBN. ${ }^{*}$ Values are significantly different from the control (SNP), based on independent $t$-test analysis $(P<0.05),{ }^{* *} P<0.01,{ }^{* * *} P<0.001$. Mean \pm SEM.

in the presence of both concentrations of SNP $(1 \mathrm{mM}$ and $10 \mu \mathrm{M})$. Pretreatment with ODQ inhibited SNP $(1 \mathrm{mM})$ induced membrane hyperpolarization $(-2.5 \pm 0.9 \mathrm{mV}, n=6$, $P<0.01)$ (Figures 4(a) and 4(c)) as well as SNP $(10 \mu \mathrm{M})$ induced depolarization $(1.5 \pm 0.4 \mathrm{mV}, n=6, P<0.001)$ (Figures 4(b) and 4(d)). These results suggest that the SNPactivated signaling pathway is dependent upon sGC.

\subsection{Effect of a Thiol-Modifying Agent on the SNP-Induced} Responses. A known alternative pathway for the biological effects of NO is the direct S-nitrosylation of critical cysteine thiol group(s) of target proteins [18]. To determine whether the SNP-evoked responses involved the direct modulation of membrane proteins by NO, we examined the effect of NEM, which blocks sulfhydryl groups, on SG neurons. Membrane hyperpolarization induced by SNP $(1 \mathrm{mM})$ was significantly decreased by pretreatment with NEM $(-4.4 \pm 0.8 \mathrm{mV}, n=5$, $P<0.05$ ) (Figures 5(a) and 5(c)). Depolarization by SNP $(10 \mu \mathrm{M})$ was also significantly inhibited by the presence of $\mathrm{NEM}(-0.1 \pm 1.4 \mathrm{mV}, n=7, P<0.05)$ (Figures $5(\mathrm{~b})$ and 5(d)). Similar results were observed for voltage clamp recordings. An inward current induced by SNP $(10 \mu \mathrm{M})$ and an outward current induced by SNP $(1 \mathrm{mM})$ were inhibited by pretreatment with NEM (data not shown). These results indicate that SNP-induced responses are mediated via direct S-nitrosylation of channel protein.

3.6. Involvement of Various $K^{+}$Channels on SNP-Induced Membrane Hyperpolarization. Different mechanisms of NOdependent effects have been reported in the literature, including the direct activation of $\mathrm{K}^{+}$channels $[1,3,19]$. Therefore, we next determined the ion channels involved in the SNP-induced hyperpolarization. Significant inhibition of hyperpolarization was observed in the presence of CTX $(-4.5$ $\pm 0.7 \mathrm{mV}, n=6, P<0.05$ ) (Figures 6(a) and 6(e)) and TEA, large-conductance $\mathrm{Ca}^{2+}$-activated $\mathrm{K}^{+}(\mathrm{BK})$ channel blockers $(-3.3 \pm 0.7 \mathrm{mV}, n=10, P<0.01)$ (Figures 6(b) and 6(e)). However, it was not significantly inhibited in the presence of apamin, small-conductance $\mathrm{Ca}^{2+}$-activated $\mathrm{K}^{+}(\mathrm{SK})$ channel blocker $(-5.8 \pm 0.7 \mathrm{mV}, n=6$ ) (Figures 6(c) and 6(e)). In 

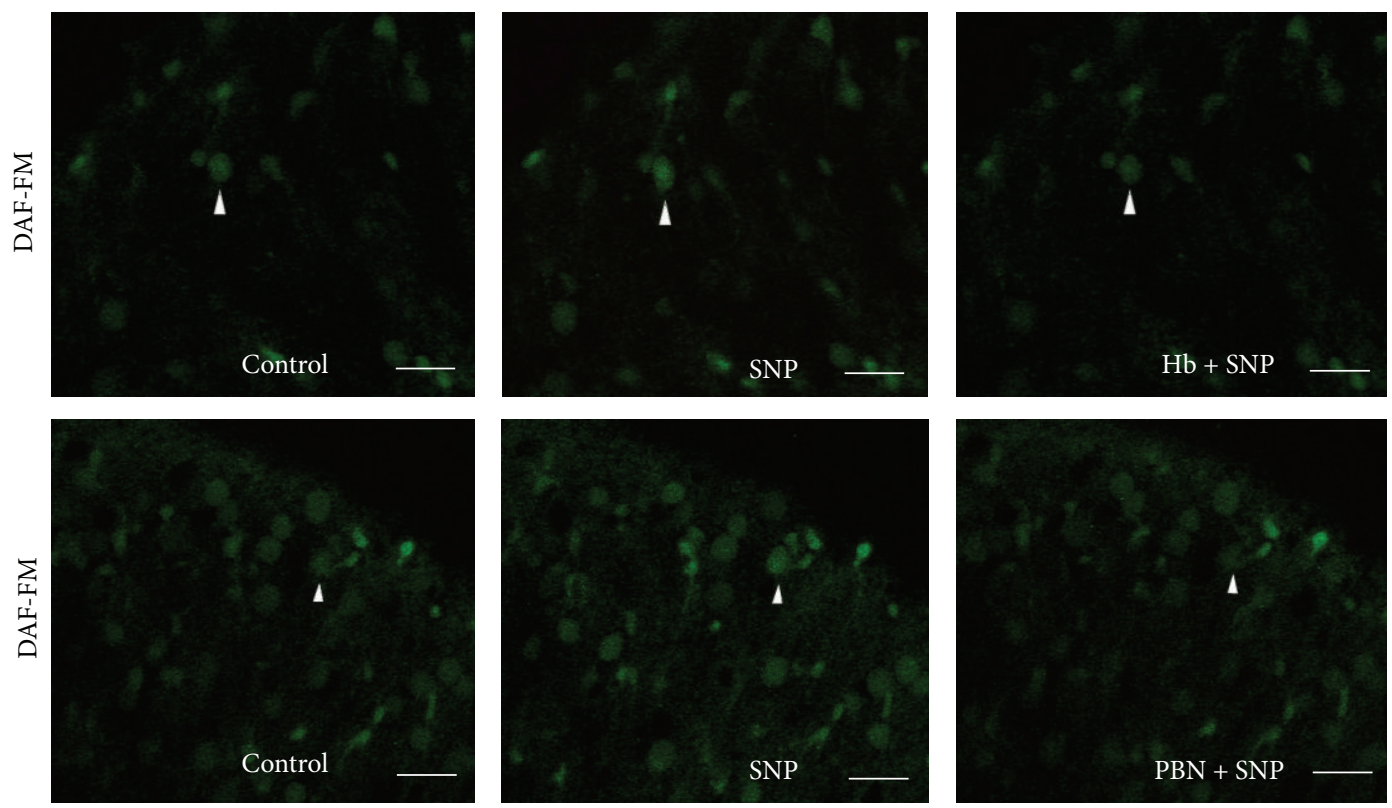

(a)
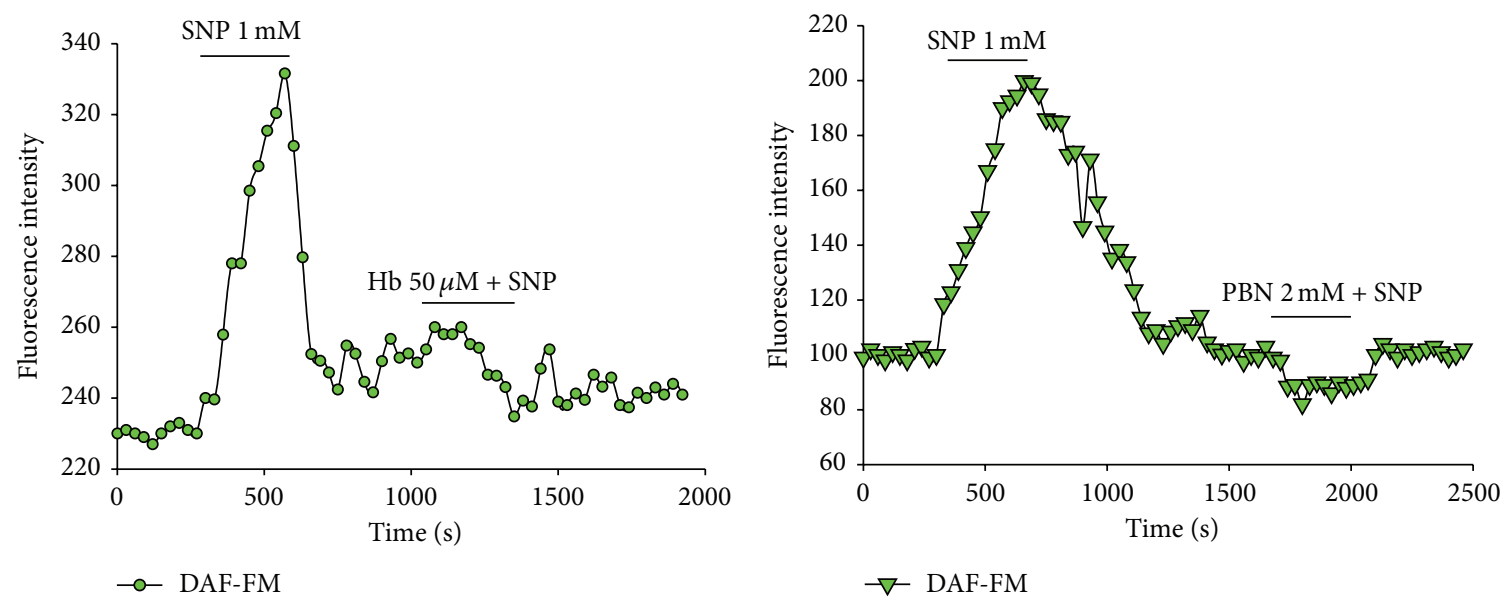

(b)

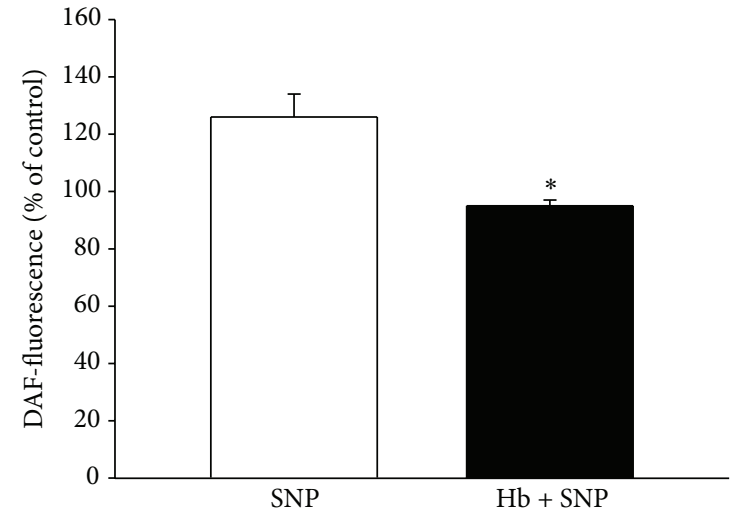

(d)

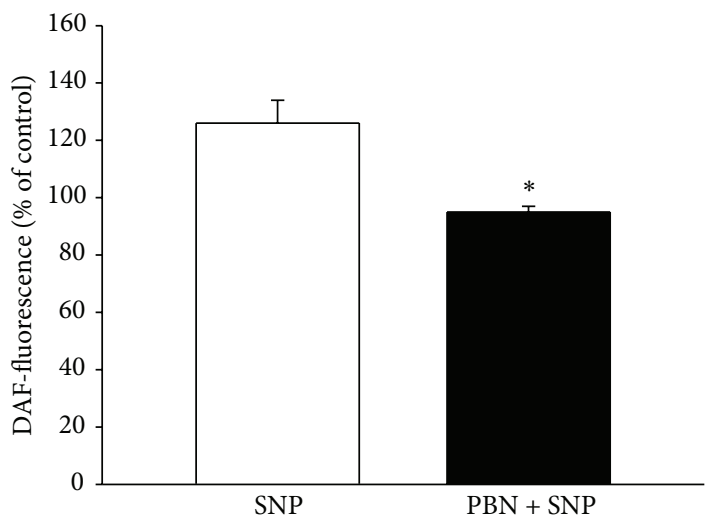

(e)

FIGURE 3: Fluorescence response of NO in DAF-FM DA-loaded spinal cord slices. (a) After addition of SNP (1 mM), fluorescence intensity increased. Hemoglobin $(50 \mu \mathrm{M})$ (upper) and PBN ( $2 \mathrm{mM})$ (lower) prevented the NO-induced fluorescence increase (scale bars: $50 \mu \mathrm{m})$. ((b), (c)) Obtained images during the time series were shown for changes in fluorescence intensity within the regions of interest (ROI) (arrows indicate ROI). ((d), (e)) The results were quantitatively analyzed as percent units of DAF fluorescence of the control. *Values are significantly different from the control (SNP), based on independent $t$-test analysis $(P<0.05)$. Mean \pm SEM. 


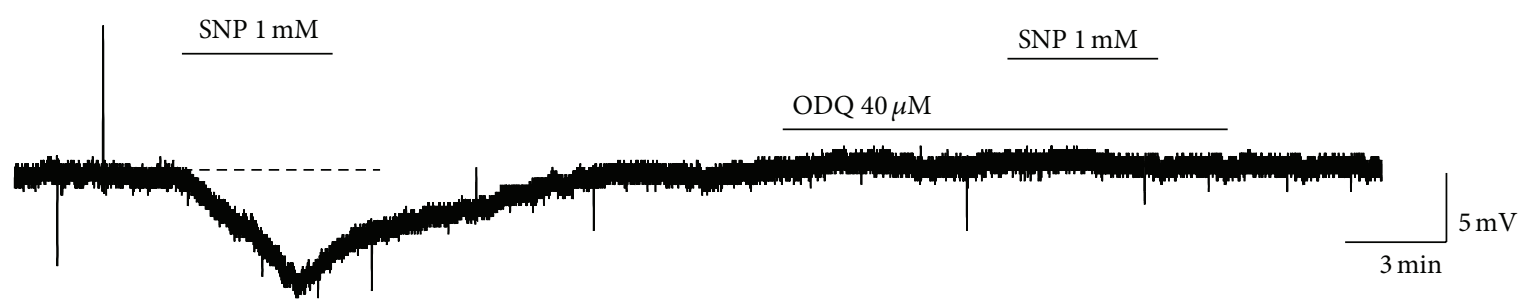

(a)

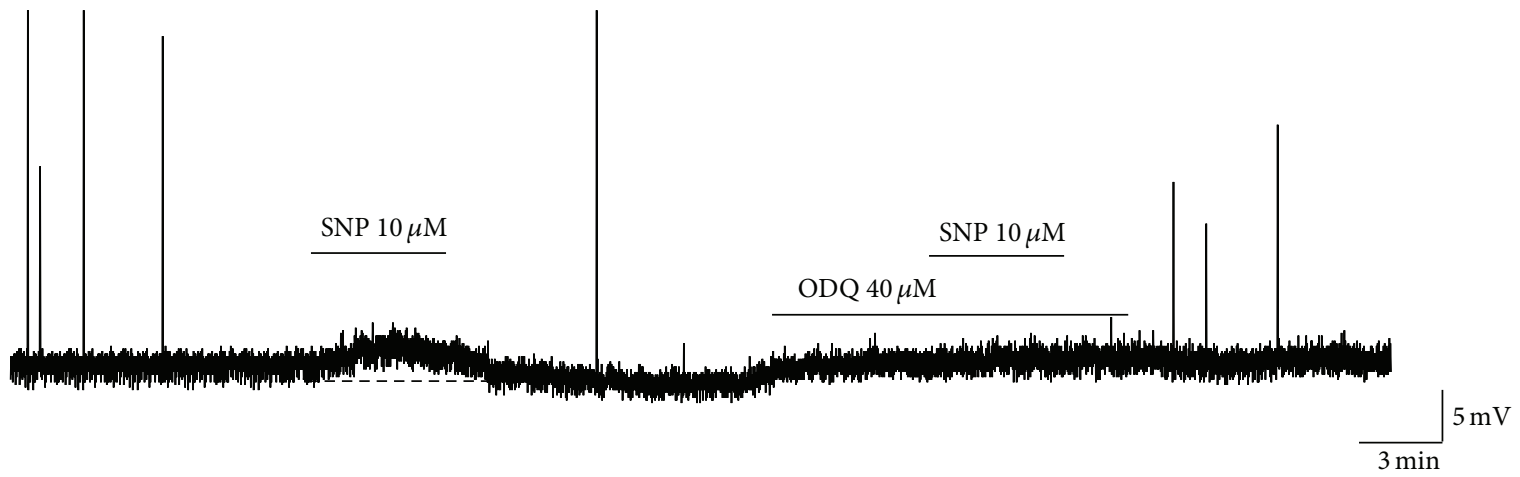

(b)

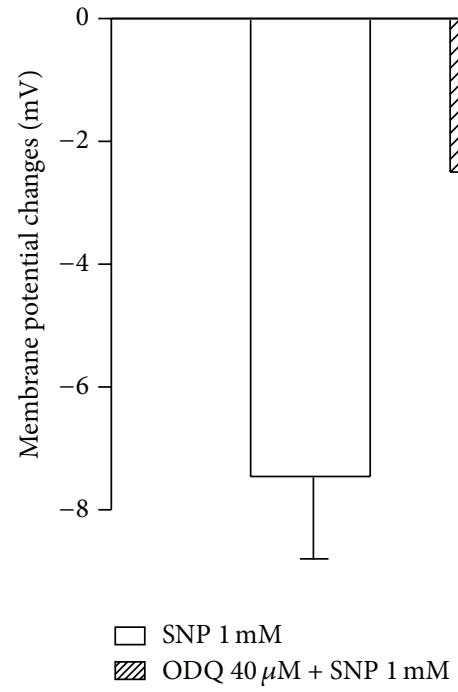

(c)
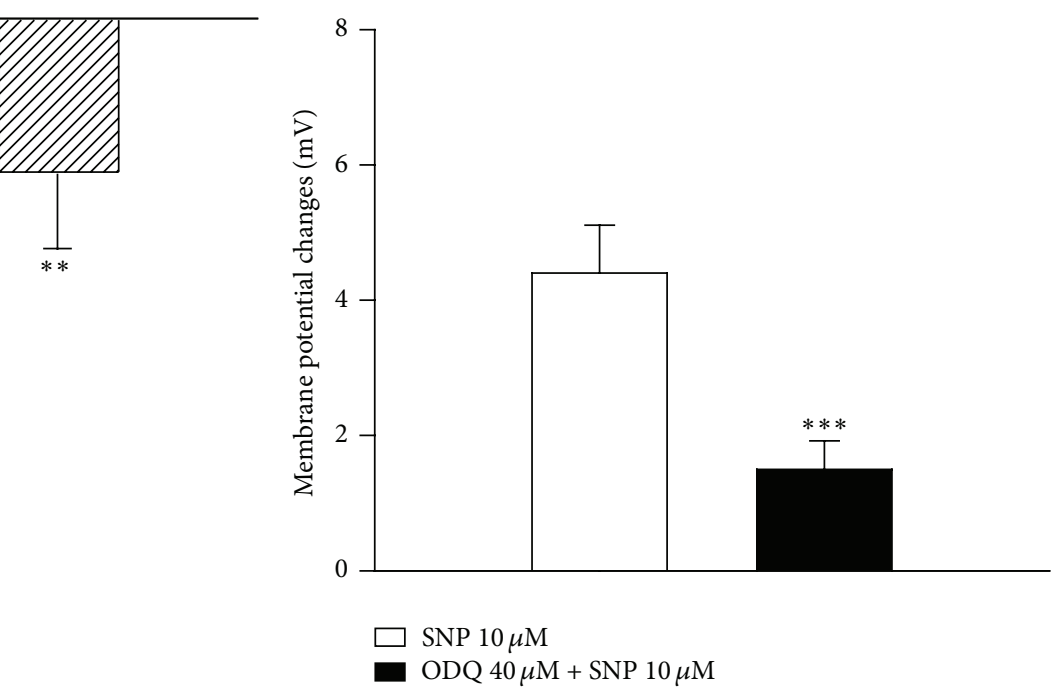

(d)

FIGURE 4: Soluble guanylyl cyclase is involved in the SNP-induced responses. (a) SNP (1 mM)-induced membrane hyperpolarization in SG neurons was blocked by ODQ $(40 \mu \mathrm{M})$. (b) Membrane depolarization by SNP $(10 \mu \mathrm{M})$ was inhibited by pretreated with ODQ. (c) Summary data obtained under the control condition of $1 \mathrm{mM}$ SNP-induced hyperpolarization and pretreatment with ODQ. (d) Summary data obtained under the control condition of $10 \mu \mathrm{M}$ SNP-induced depolarization and pretreatment with ODQ. ${ }^{* *}$ Values are significantly different from the control (SNP), based on independent $t$-test analysis $(P<0.01),{ }^{* * *} P<0.001$. Mean \pm SEM.

addition, membrane hyperpolarization was also significantly inhibited by application of glibenclamide, an ATP-sensitive $\mathrm{K}^{+}\left(\mathrm{K}_{\text {ATP }}\right)$ channel blocker $(-3.3 \pm 0.5 \mathrm{mV}, n=6, P<$ 0.001 ) (Figures 6(d) and 6(e)). These observations suggest that NO generated its effect through the activation of various $\mathrm{K}^{+}$channels.

3.7. Involvement of a Nonspecific Cation Channel in Membrane Depolarization Induced by SNP. Recently, it was reported that SNP depolarizes the membrane potential of SG neurons and that this effect is inhibited by the presence of $1 \mathrm{mM} \mathrm{Cs}^{+}$[20]. Based on this report, we tested whether SNP-induced depolarization was caused by the activation of hyperpolarization-activated $\mathrm{K}^{+}$channel. Depolarization induced by a low concentration of SNP $(10 \mu \mathrm{M})$ was not inhibited by the presence of $1 \mathrm{mM} \mathrm{Cs}^{+}(4.5 \pm 0.7 \mathrm{mV}, n=7)$ (Figures $7(\mathrm{a})$ and $7(\mathrm{c})$ ). However, it was significantly blocked by the presence of a nonspecific cation channel blocker, lanthanum $(1.4 \pm 0.5 \mathrm{mV}, n=5, P<0.01)$ (Figures $7(\mathrm{~b})$ 


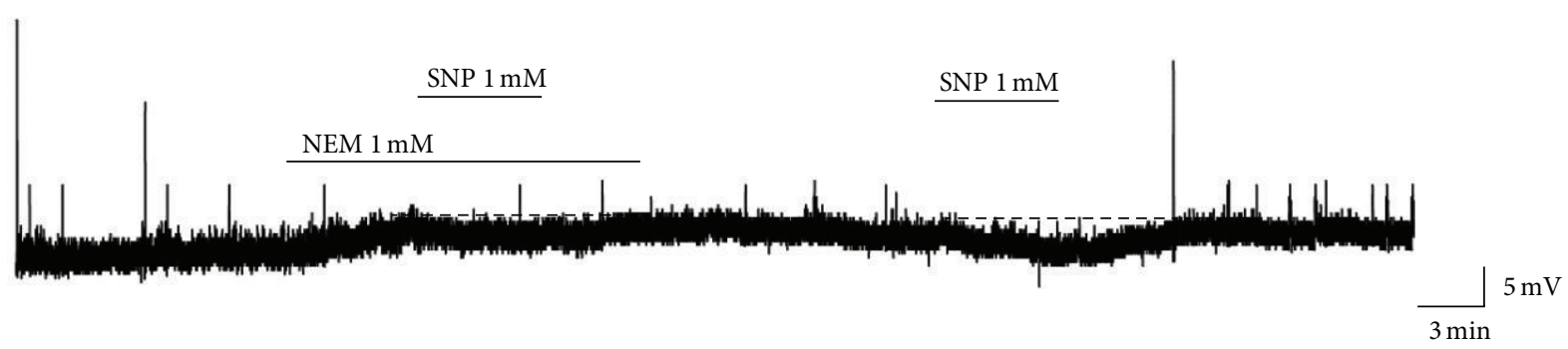

(a)

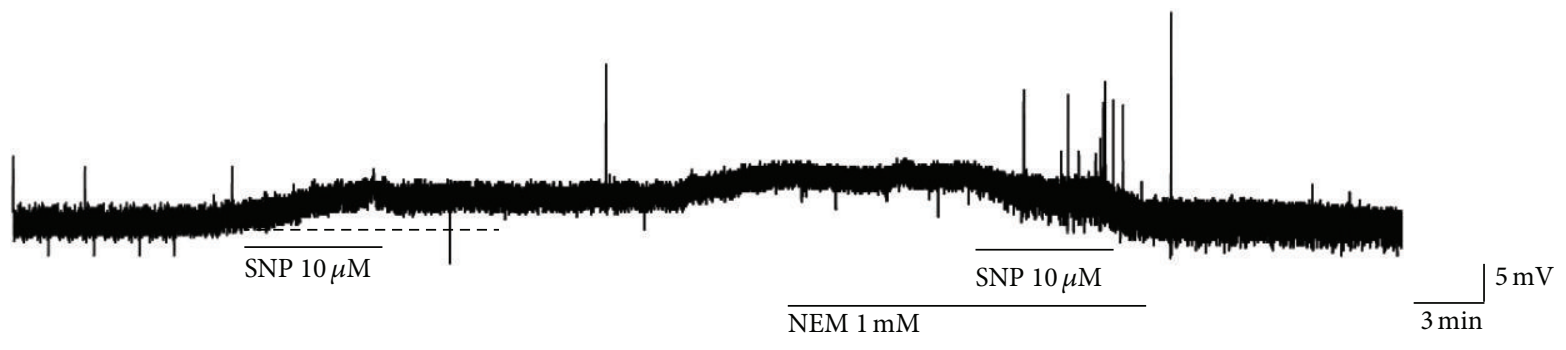

(b)

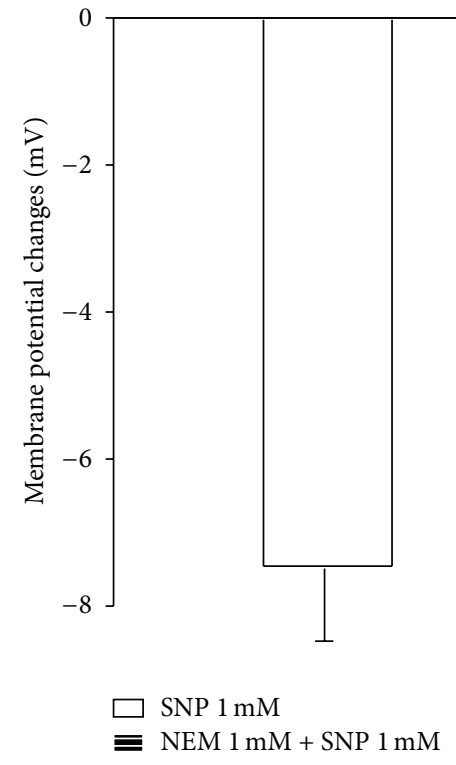

(c)

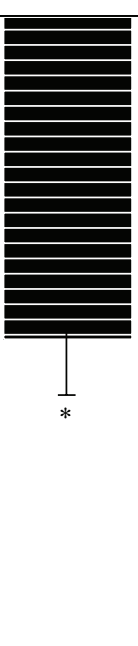

(1)

(c)

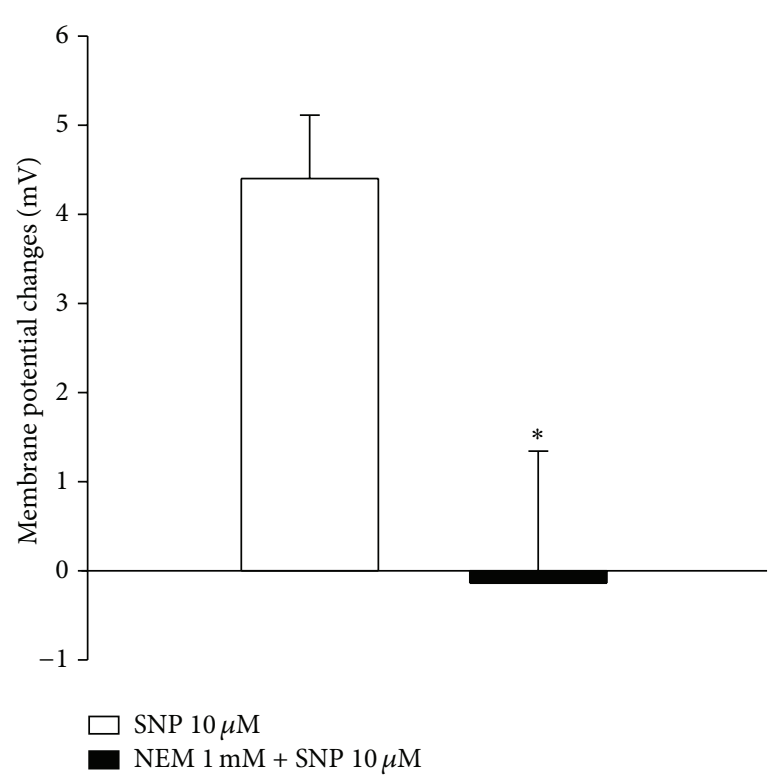

(d)

FIGURE 5: Effect of NEM, a thiol-modifying agent, on SNP-induced membrane potential changes. (a) Membrane hyperpolarization, induced by SNP $(1 \mathrm{mM})$, was decreased by the presence of NEM. (b) SNP $(10 \mu \mathrm{M})$-induced depolarization was decreased by the application of NEM. (c) Summary of data obtained under the control condition of SNP-induced hyperpolarization and pretreatment with NEM. (d) Summary of data obtained under the control condition of SNP-induced depolarization and pretreatment with NEM. *Values are significantly different from the control (SNP), based on independent $t$-test analysis $(P<0.05)$. Mean \pm SEM.

and $7(\mathrm{c}))$. These results suggest that depolarization induced by a low concentration of SNP $(10 \mu \mathrm{M})$ did not involve hyperpolarization-activated $\mathrm{K}^{+}$channels but instead involved activation of a nonspecific cation channel.

\section{Discussion}

NO donors as well as endogenously produced NO exert various physiological effects, including smooth muscle relaxation, apoptosis, neurotransmitter release, and neurotoxicity
[6]. NO is produced in the spinal dorsal horn neurons in response to extensive nociceptive input thereby contributing to central sensitization and persistent pain $[21,22]$.

Recently, a dual effect of $\mathrm{NO}$ on pain transmission was reported. Kawabata et al. [23] observed that NO induces a nociceptive or antinociceptive effect in a dosedependent manner in mice. These authors demonstrated that injection of a low dose of L-arginine enhanced the nociceptive response, whereas administration of a high dose suppressed the nociceptive effect. In contrast, $\mathrm{Li}$ and Qi 


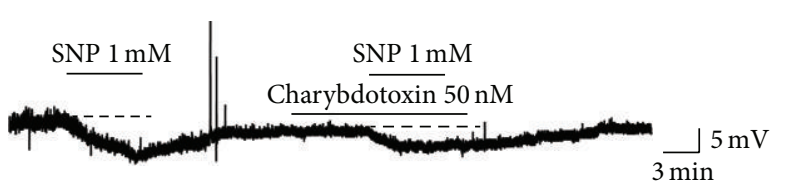

(a)

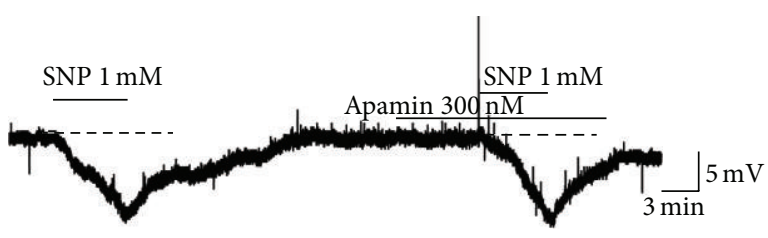

(c)

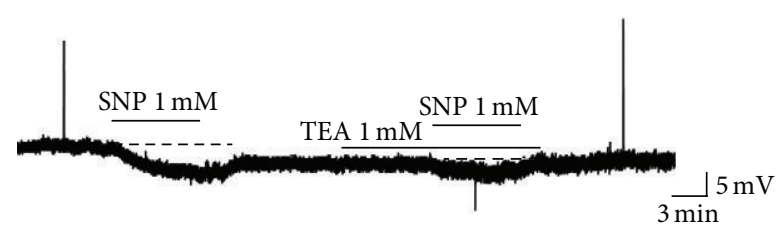

(b)
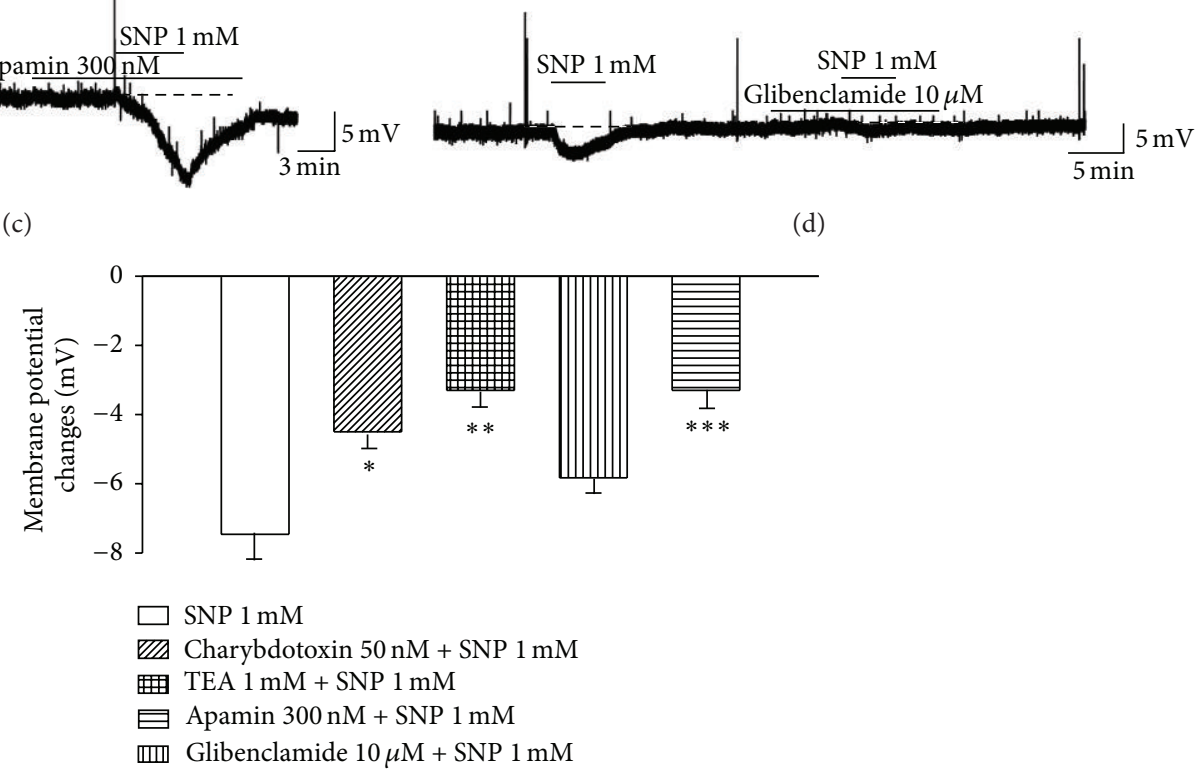

(d)

(e)

FIGURE 6: Involvement of various $\mathrm{K}^{+}$channels in SNP-induced membrane hyperpolarization. ((a), (b)) Changes in membrane potential evoked by SNP $(1 \mathrm{mM})$ were significantly inhibited by CTX and TEA, BK channel blockers. (c) Membrane hyperpolarization was not significantly inhibited by the presence of apamin, a SK channel blocker. (d) Membrane hyperpolarization was inhibited by application of glibenclamide, a $\mathrm{K}_{\text {ATP }}$ channel blocker. (e) Bar graphs show the membrane potential changes elicited by application of various $\mathrm{K}^{+}$channel blockers. ${ }^{*}$ Values are significantly different from the control (SNP), based on independent $t$-test analysis $(P<0.05),{ }^{* *} P<0.01,{ }^{* * *} P<0.001$. Mean \pm SEM.

[24] demonstrated that intrathecal administration of low doses of L-arginine inhibited the nociceptive responses evoked by the intraplantar injection of formalin in rats, whereas high doses of the NO precursor increased this response. Furthermore, using a model of neuropathic pain in rats, Sousa and Prado [25] showed that intrathecal administration of 3-morpholinosydnonimine (SIN-1), a NO donor, produces a dual dose-dependent effect. These authors reported that low intrathecal doses of SIN-1 reduced the mechanical allodynia evoked by sciatic nerve ligation, whereas higher doses enhanced the allodynia or had no effect.

Pehl and Schmid [26] investigated the effects of different NO donors on spontaneously active neurons in the rat spinal cord using extracellular recording. They reported that NO causes direct excitation or inhibition of the electrical activity of spinal neurons. Discrepancies might be because of the differences regarding the doses of NO donors, the model used for pain evaluation, and experimental animal used in the studies [3]. Results, similar to those mentioned above, were also demonstrated in the present study, whereby application of different SNP concentrations produced a dual effect on the membrane potential of the SG neurons (Figure 1).

ROS such as $\mathrm{O}_{2}{ }^{--}, \mathrm{H}_{2} \mathrm{O}_{2}, \mathrm{NO}$, and $\mathrm{ONOO}^{-}$are closely related to central sensitization $[9,10]$. This study explored whether ROS are involved in the SNP-induced changes in neuronal excitability of SG neurons, produced by each concentration of SNP $(1 \mathrm{mM}$ or $10 \mu \mathrm{M})$, by applying a strong ROS scavenger, PBN. Application of PBN significantly blocked the response evoked by both concentrations of SNP (Figure 2). It seems possible that $\mathrm{NO}$ can react with endogenously generated $\mathrm{O}_{2}{ }^{--}$to produce highly toxic $\mathrm{ONOO}^{-}$. ONOO has been proposed as a converged downstream molecule of $\mathrm{O}_{2}{ }^{--}$and NO in persistent pain conditions [12]. In this study, we did not use an $\mathrm{ONOO}^{-}$decomposition catalyst to verify whether $\mathrm{ONOO}^{-}$influences SNP-induced responses. Therefore, we cannot exclude the possibility that $\mathrm{ONOO}^{-}$can modulate the excitability of SG neurons. However, Kim et al. [22] demonstrated that $\mathrm{NO}$ and $\mathrm{O}_{2}{ }^{--}$operate independently, while both are contributing to the same persistent pain.

Several fluorescent probes have been designed to measure NO in biological samples [27]. The most widely used and best 


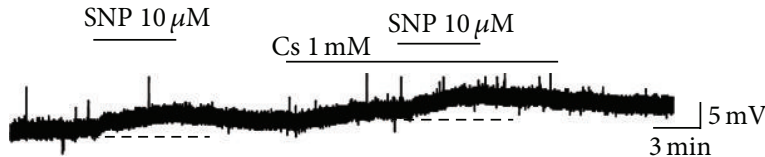

(a)

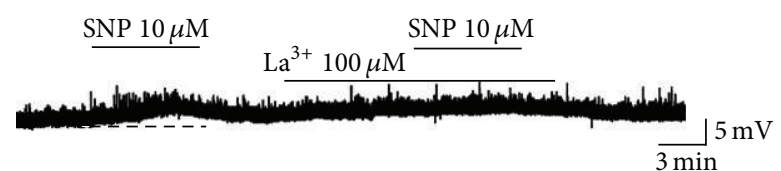

(b)

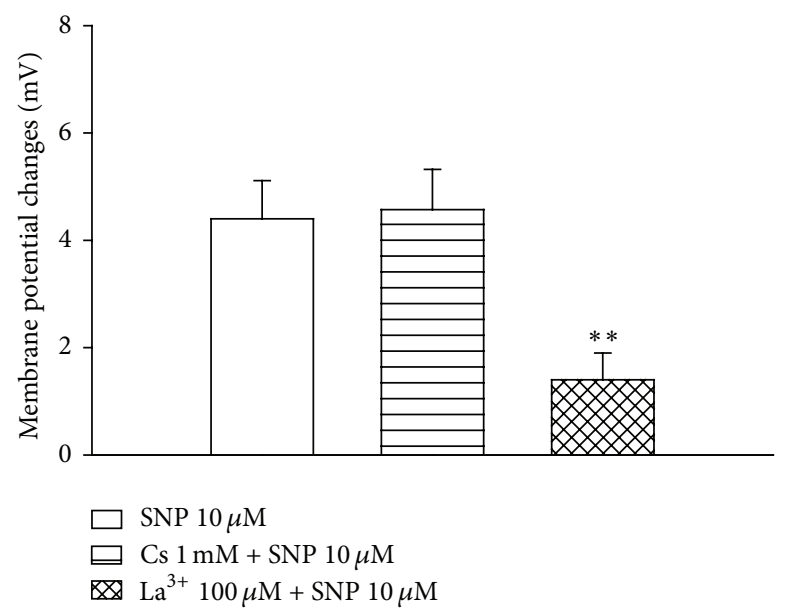

(c)

FIGURE 7: Involvement of a nonspecific cation channel in the membrane depolarization induced by SNP. (a) Membrane depolarization evoked by SNP $(10 \mu \mathrm{M})$ was not inhibited by the presence of $1 \mathrm{mM} \mathrm{Cs}^{+}$. (b) Depolarization evoked by SNP was significantly inhibited by La ${ }^{3+}$, a nonspecific cation channel blocker. (c) Bar graphs show the membrane potential changes induced by pretreatment with $\mathrm{Cs}^{+}$and $\mathrm{La}^{3+}$. ${ }^{* *}$ Values are significantly different from the control (SNP), based on independent $t$-test analysis $(P<0.01)$. Mean \pm SEM.

characterized probes are 4,5-diaminofluorescein (DAF-2) and 4-amino-5-methylamino-2,7-difluorofluorescein (DAFFM), both of which react with $\mathrm{NO}$ to form green fluorescent triazole products [28]. In this study, we confirmed the presence of SNP-induced intracellular NO production using DAF-FM. As shown in Figure 3, NO production was increased by addition of SNP in the spinal cord slices. Similar to our finding, it was previously reported that the fluorescence of DAF-FM increases in a dose- and timedependent manner upon incubation with SNP [29]. The SNPinduced fluorescence increase observed in this study was reduced by $\mathrm{Hb}$, a NO scavenger (Figures 3(a), 3(b), and 3(d)). The scavenging effect of $\mathrm{Hb}$ on $\mathrm{NO}$ has been demonstrated in several experiments [30, 31]. Moreover, we successfully used PBN, a ROS scavenger, to inhibit NO activity. Similar to a previous study [22], this result demonstrates that NOinduced fluorescence is prevented by PBN.

NO activates guanylate cyclase, which is responsible for an increase in intracellular levels of cGMP. Sousa and Prado [25] demonstrated that pretreatment with ODQ, a selective sGC inhibitor, practically abolishes the antinociceptive and pronociceptive effect mediated by an intrathecally applied NO donor. On the basis of their findings, in this study, ODQ was applied to each concentration of SNP to investigate the involvement of the NO-cGMP signaling pathway. Similar to previous reports, application of ODQ significantly blocked the response evoked by both concentrations of SNP (Figure 4). These findings demonstrate that SNP mediates its effect through a $\mathrm{NO} / \mathrm{sGC} / \mathrm{cGMP}$ pathway.
Besides activating the indirect cGMP-signaling pathway, NO can also directly modify channel proteins by Snitrosylation $[1,18]$. S-Nitrosylation is emerging as an important form of posttranslational modification of ion channels. It provides a route by which $\mathrm{NO}$ can regulate electrical activity without stimulating production of cGMP. Kawano et al. [18] reported that nitric oxide activates $\mathrm{K}_{\mathrm{ATP}}$ channels in mammalian sensory neurons by direct S-nitrosylation. They showed that inhibition of sGC and PKG failed to block this activation by NO. In addition, they reported that $\mathrm{NO}$ activation of $\mathrm{K}_{\mathrm{ATP}}$ currents is inhibited by thiolalkylating agents, which demonstrates that $\mathrm{S}$-nitrosylation is needed for NO action. In the present study, to determine whether SNP can directly modulate SG neurons through Snitrosylation, NEM was applied as an S-nitrosylation blocker (Figure 5). The responses induced by both concentrations of SNP were significantly inhibited by NEM. These findings suggest that SNP mediates its effects via direct S-nitrosylation of membrane proteins in SG neurons.

$\mathrm{K}^{+}$channel activation may be elicited by both $\mathrm{NO}$ and/or NO redox forms. Both PKG and S-nitrosylation enhance the activity of BK channels. In addition, cGMP modulates the activity of a delayed rectifier $\mathrm{K}^{+}$channel and $\mathrm{K}_{\mathrm{ATP}}$ channels through activation of PKG $[1,32-34]$. To test whether NO activates $\mathrm{K}^{+}$channels to induce changes in membrane potential, various $\mathrm{K}^{+}$channel blockers were applied. Hyperpolarization evoked by SNP $(1 \mathrm{mM})$ was significantly inhibited by pretreatment with CTX and TEA, BK channel blockers, and glibenclamide, a specific $\mathrm{K}_{\mathrm{ATP}}$ channel blocker, but was 
not altered by pretreatment with apamin, a SK channel blocker (Figure 6). These findings indicate that NO-induced membrane hyperpolarization involves the activation of both $\mathrm{BK}$, and $\mathrm{K}_{\mathrm{ATP}}$ channel.

Kim et al. [20] observed that application of SNP $(500 \mu \mathrm{M})$ induced membrane depolarization in SG neurons and reported that this effect was elicited by a hyperpolarizationactivated inward current. On the basis of this finding, we tested whether SNP $(10 \mu \mathrm{M})$-induced depolarization was caused by the activation of a hyperpolarization-activated $\mathrm{K}^{+}$channel by pretreating SG neurons with $\mathrm{Cs}^{+}$. However, membrane depolarization evoked by a low concentration of SNP was not affected by pretreatment with $\mathrm{Cs}^{+}$. Similar to our study, Sun et al. [35] demonstrated that peripheral ZD7288, a hyperpolarization-activated $\mathrm{K}^{+}$channel blocker, blocked neuropathic pain while intrathecal administration of ZD7288 did not. Next, we used $\mathrm{La}^{3+}$, a nonspecific cation channel blocker, to block the membrane depolarization evoked by SNP. The membrane-depolarizing effect of SNP was significantly inhibited by pretreatment with $\mathrm{La}^{3+}$ (Figure 7). Recently, it was reported that NO donors could activate nonspecific cation channels including TRPV1 and TRPA1 by direct S-nitrosylation and indirect sGC/PKG pathway $[8,36$, 37]. These results indicate that a nonspecific cation channel is involved in NO-related transmission of pain.

\section{Conclusion}

Substantia gelatinosa neurons in the dorsal horn are critical for mediating nociceptive signals. The dual effect of NO identified in SG neurons is important for the transmission of pain. The findings of this study suggest that NO elicits excitatory and inhibitory effects on SG neurons in a concentrationdependent manner via activation of various ion channels by direct S-nitrosylation and sGC activation.

\section{Conflict of Interests}

The authors declare that there is no conflict of interests regarding the publication of this article.

\section{Acknowledgment}

This study was supported by the Wonkwang University in 2011.

\section{References}

[1] G. P. Ahern, V. A. Klyachko, and M. B. Jackson, "cGMP and Snitrosylation: two routes for modulation of neuronal excitability by NO," Trends in Neurosciences, vol. 25, no. 10, pp. 510-517, 2002.

[2] V. Calabrese, C. Mancuso, M. Calvani, E. Rizzarelli, D. A. Butterfield, and A. M. Giuffrida Stella, "Nitric oxide in the central nervous system: neuroprotection versus neurotoxicity," Nature Reviews Neuroscience, vol. 8, no. 10, pp. 766-775, 2007.

[3] Y. Cury, G. Picolo, V. P. Gutierrez, and S. H. Ferreira, "Pain and analgesia: the dual effect of nitric oxide in the nociceptive system," Nitric Oxide, vol. 25, no. 3, pp. 243-254, 2011.
[4] J. V. Esplugues, "NO as a signalling molecule in the nervous system," British Journal of Pharmacology, vol. 135, no. 5, pp. 1079-1095, 2002.

[5] N. Olson and A. Van Der Vliet, "Interactions between nitric oxide and hypoxia-inducible factor signaling pathways in inflammatory disease," Nitric Oxide, vol. 25, no. 2, pp. 125-137, 2011.

[6] J. W. Denninger and M. A. Marletta, "Guanylate cyclase and the NO/cGMP signaling pathway," Biochimica et Biophysica Acta, vol. 1411, no. 2-3, pp. 334-350, 1999.

[7] A. Rudkouskaya, V. Sim, A. A. Shah, P. J. Feustel, D. Jourd'heuil, and A. A. Mongin, "Long-lasting inhibition of presynaptic metabolism and neurotransmitter release by protein Snitrosylation," Free Radical Biology \& Medicine, vol. 49, no. 5, pp. 757-769, 2010.

[8] Y. J. Jin, J. Kim, and J. Y. Kwak, "Activation of the cGMP/protein kinase $G$ pathway by nitric oxide can decrease TRPV1 activity in cultured rat dorsal root ganglion neurons," The Korean Journal of Physiology \& Pharmacology, vol. 16, no. 3, pp. 211-217, 2012.

[9] H. K. Kim, S. K. Park, J.-L. Zhou et al., "Reactive oxygen species (ROS) play an important role in a rat model of neuropathic pain," Pain, vol. 111, no. 1-2, pp. 116-124, 2004.

[10] H. K. Kim, J. H. Kim, X. Gao et al., "Analgesic effect of vitamin $\mathrm{E}$ is mediated by reducing central sensitization in neuropathic pain," Pain, vol. 122, no. 1-2, pp. 53-62, 2006.

[11] Y. Guan, M. Yaster, S. N. Raja, and Y.-X. Tao, "Genetic knockout and pharmacologic inhibition of neuronal nitric oxide synthase attenuate nerve injury-induced mechanical hypersensitivity in mice," Molecular Pain, vol. 3, article no. 29, 2007.

[12] M. Tanabe, Y. Nagatani, K. Saitoh, K. Takasu, and H. Ono, "Pharmacological assessments of nitric oxide synthase isoforms and downstream diversity of NO signaling in the maintenance of thermal and mechanical hypersensitivity after peripheral nerve injury in mice," Neuropharmacology, vol. 56, no. 3, pp. 702-708, 2009.

[13] Y.-C. Chu, Y. Guan, J. Skinner, S. N. Raja, R. A. Johns, and Y.-X. Tao, "Effect of genetic knockout or pharmacologic inhibition of neuronal nitric oxide synthase on complete Freund's adjuvantinduced persistent pain," Pain, vol. 119, no. 1-3, pp. 113-123, 2005.

[14] T. J. Coderre and K. Yashpal, "Intracellular messengers contributing to persistent nociception and hyperalgesia induced by L-glutamate and substance P in the rat formalin pain model," The European Journal of Neuroscience, vol. 6, no. 8, pp. 13281334, 1994.

[15] S. T. Meller, C. P. Cummings, R. J. Traub, and G. F. Gebhart, "The role of nitric oxide in the development and maintenance of the hyperalgesia produced by intraplantar injection of carrageenan in the rat," Neuroscience, vol. 60, no. 2, pp. 367-374, 1994.

[16] E. Chung, B. Burke, A. J. Bieber, J. C. Doss, Y. Ohgami, and R. M. Quock, "Dynorphin-mediated antinociceptive effects of 1-arginine and SIN-1 (an NO donor) in mice," Brain Research Bulletin, vol. 70, no. 3, pp. 245-250, 2006.

[17] I. D. G. Duarte, B. B. Lorenzetti, and S. H. Ferreira, "Peripheral analgesia and activation of the nitric oxide-cyclic GMP pathway," European Journal of Pharmacology, vol. 186, no. 2-3, pp. 289-293, 1990.

[18] T. Kawano, V. Zoga, M. Kimura et al., "Nitric oxide activates ATP-sensitive potassium channels in mammalian sensory neurons: action by direct S-nitrosylation," Molecular Pain, vol. 5, article no. 12, 2009.

[19] V. M. Bolotina, S. Najibi, J. J. Palacino, P. J. Pagano, and R. A. Cohen, "Nitric oxide directly activates calcium-dependent 
potassium channels in vascular smooth muscle," Nature, vol. 368, no. 6474, pp. 850-853, 1994.

[20] H. Y. Kim, S. J. Kim, J. Kim, S. B. Oh, H. Cho, and S. J. Jung, "Effect of nitric oxide on hyperpolarization-activated current in substantia gelatinosa neurons of rats," Biochemical and Biophysical Research Communications, vol. 338, no. 3, pp. 1648-1653, 2005.

[21] Y. W. Yoon, B. Sung, and J. M. Chung, "Nitric oxide mediates behavioral signs of neuropathic pain in an experimental rat model," NeuroReport, vol. 9, no. 3, pp. 367-372, 1998.

[22] H. Y. Kim, J. Wang, Y. Lu, J. M. Chung, and K. Chung, "Superoxide signaling in pain is independent of nitric oxide signaling," NeuroReport, vol. 20, no. 16, pp. 1424-1428, 2009.

[23] A. Kawabata, S. Manabe, Y. Manabe, and H. Takagi, "Effect of topical administration of L-arginine on formalin-induced nociception in the mouse: a dual role of peripherally formed NO in pain modulation," British Journal of Pharmacology, vol. 112, no. 2, pp. 547-550, 1994.

[24] K. Li and W.-X. Qi, "Effects of multiple intrathecal administration of L-arginine with different doses on formalin-induced nociceptive behavioral responses in rats," Neuroscience Bulletin, vol. 26, no. 3, pp. 211-218, 2010.

[25] A. M. Sousa and W. A. Prado, "The dual effect of a nitric oxide donor in nociception," Brain Research, vol. 897, no. 1-2, pp. 9-19, 2001.

[26] U. Pehl and H. A. Schmid, "Electrophysiological responses of neurons in the rat spinal cord to nitric oxide," Neuroscience, vol. 77, no. 2, pp. 563-573, 1997.

[27] Z. Lacza, E. M. Horváth, E. Pankotai et al., "The novel redfluorescent probe DAR-4M measures reactive nitrogen species rather than NO," Journal of Pharmacological and Toxicological Methods, vol. 52, no. 3, pp. 335-340, 2005.

[28] H. Kojima, N. Nakatsubo, K. Kikuchi et al., "Detection and imaging of nitric oxide with novel fluorescent indicators: diaminofluoresceins," Analytical Chemistry, vol. 70, no. 13, pp. 2446-2453, 1998.

[29] A. Balcerczyk, M. Soszynski, and G. Bartosz, "On the specificity of 4-amino-5-methylamino-2', $7^{\prime}$-difluorofluorescein as a probe for nitric oxide," Free Radical Biology \& Medicine, vol. 39, no. 3, pp. 327-335, 2005.

[30] L. Yu, P. E. Gengaro, M. Niederberger, T. J. Burke, and R. W. Schrier, "Nitric oxide: a mediator in rat tubular hypoxia/ reoxygenation injury," Proceedings of the National Academy of Sciences of the United States of America, vol. 91, no. 5, pp. 1691$1695,1994$.

[31] L. R. Silveira, L. Pereira-Da-Silva, C. Juel, and Y. Hellsten, "Formation of hydrogen peroxide and nitric oxide in rat skeletal muscle cells during contractions," Free Radical Biology \& Medicine, vol. 35, no. 5, pp. 455-464, 2003.

[32] C. G. Nichols, "K $\mathrm{K}_{\text {ATP }}$ channels as molecular sensors of cellular metabolism," Nature, vol. 440, no. 7083, pp. 470-476, 2006.

[33] O. Behrend, C. Schwark, T. Kunihiro, and M. Strupp, "Cyclic GMP inhibits and shifts the activation curve of the delayed rectifier (IK1) of type I mammalian vestibular hair cells," NeuroReport, vol. 8, no. 12, pp. 2687-2690, 1997.

[34] J. Han, N. Kim, E. Kim, W.-K. Ho, and Y. E. Earm, "Modulation of ATP-sensitive potassium channels by cGMP-dependent protein kinase in rabbit ventricular myocytes," Journal of Biological Chemistry, vol. 276, no. 25, pp. 22140-22147, 2001.

[35] Q. Sun, G.-G. Xing, H.-Y. Tu, J.-S. Han, and Y. Wan, "Inhibition of hyperpolarization-activated current by ZD7288 suppresses ectopic discharges of injured dorsal root ganglion neurons in a rat model of neuropathic pain," Brain Research, vol. 1032, no. 1-2, pp. 63-69, 2005.

[36] T. Miyamoto, A. E. Dublin, M. J. Petrus, and A. Patapoutian, "TRPV1 and TRPA1 mediate peripheral nitric oxide-induced nociception in mice," PLoS ONE, vol. 4, no. 10, Article ID e7596, 2009.

[37] T. Yoshida, R. Inoue, T. Morii et al., "Nitric oxide activates TRP channels by cysteine S-nitrosylation," Nature Chemical Biology, vol. 2, no. 11, pp. 596-607, 2006. 

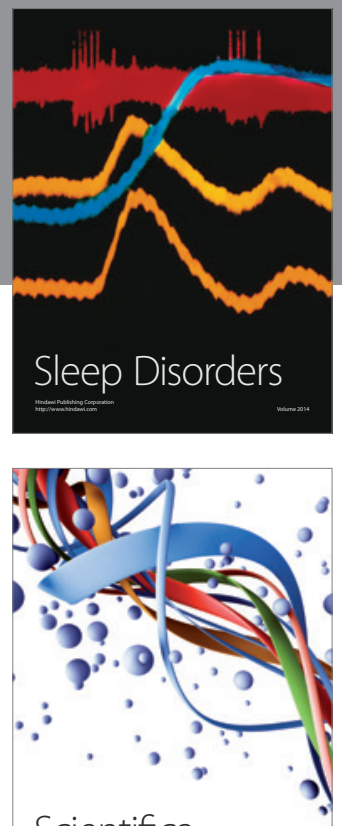

Scientifica
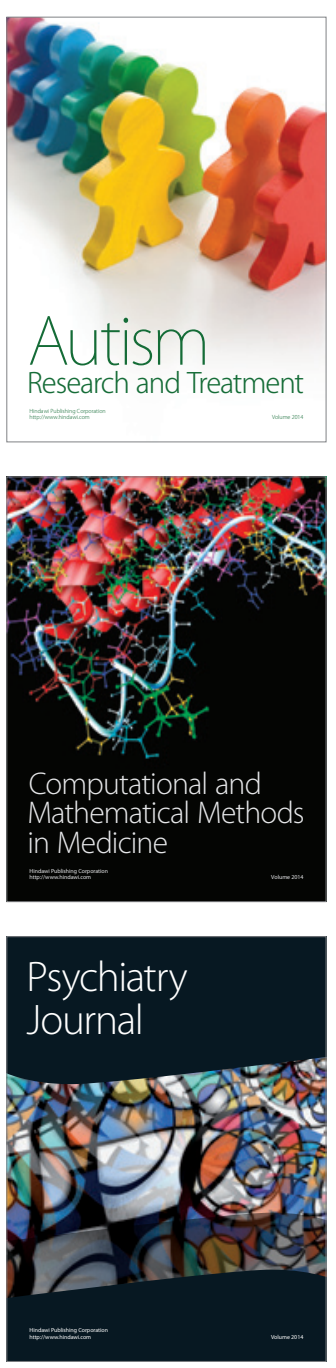
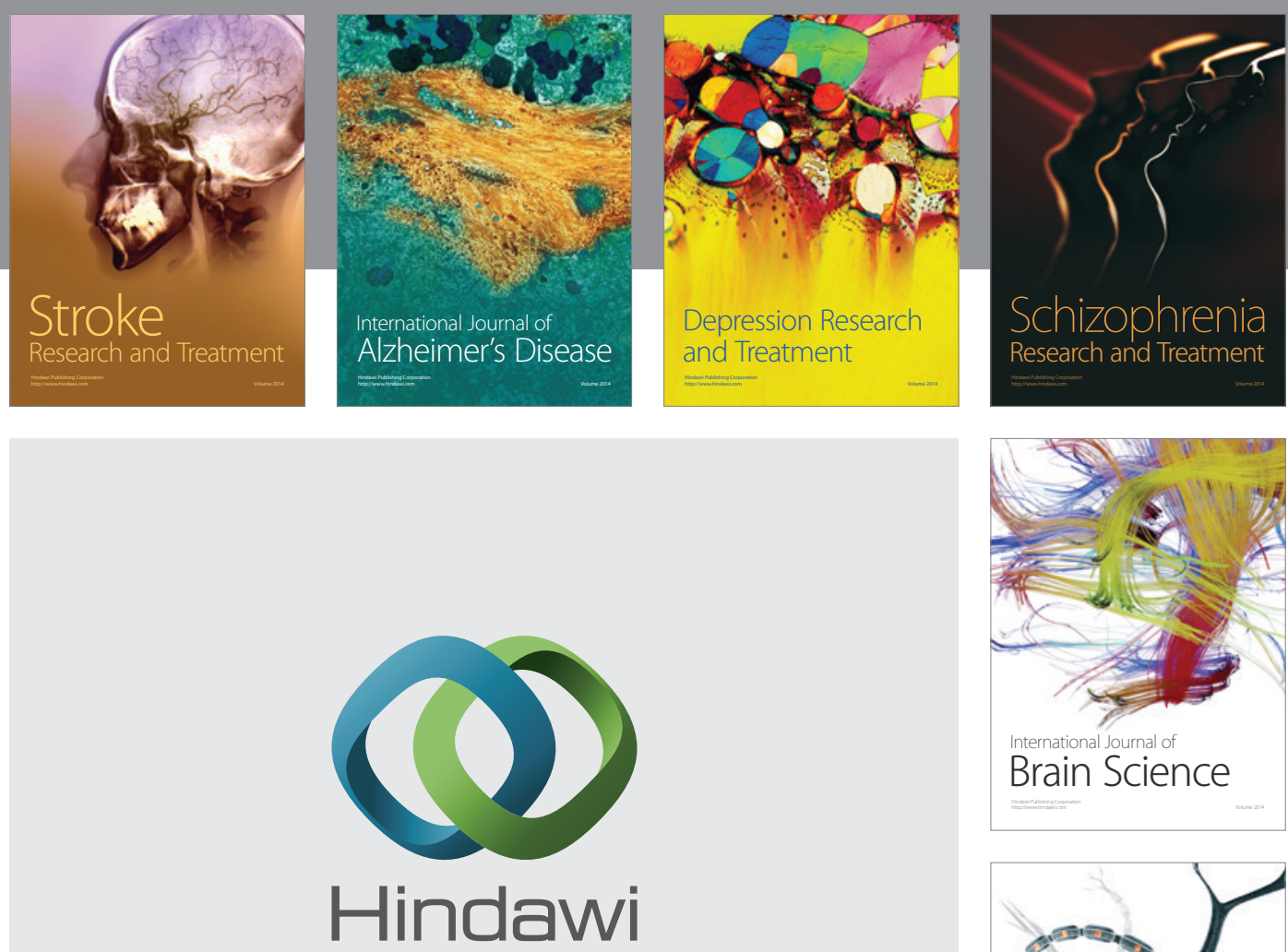

Submit your manuscripts at

http://www.hindawi.com
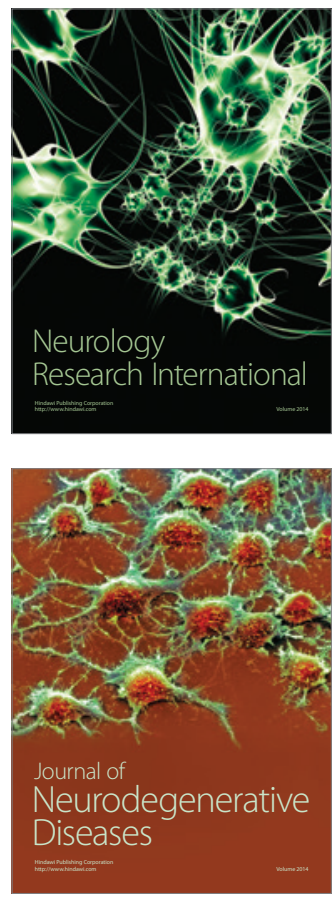

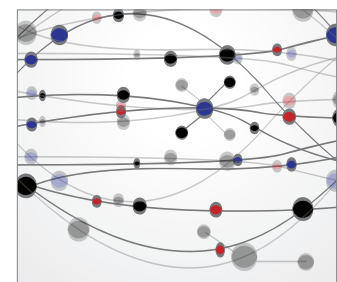

The Scientific World Journal
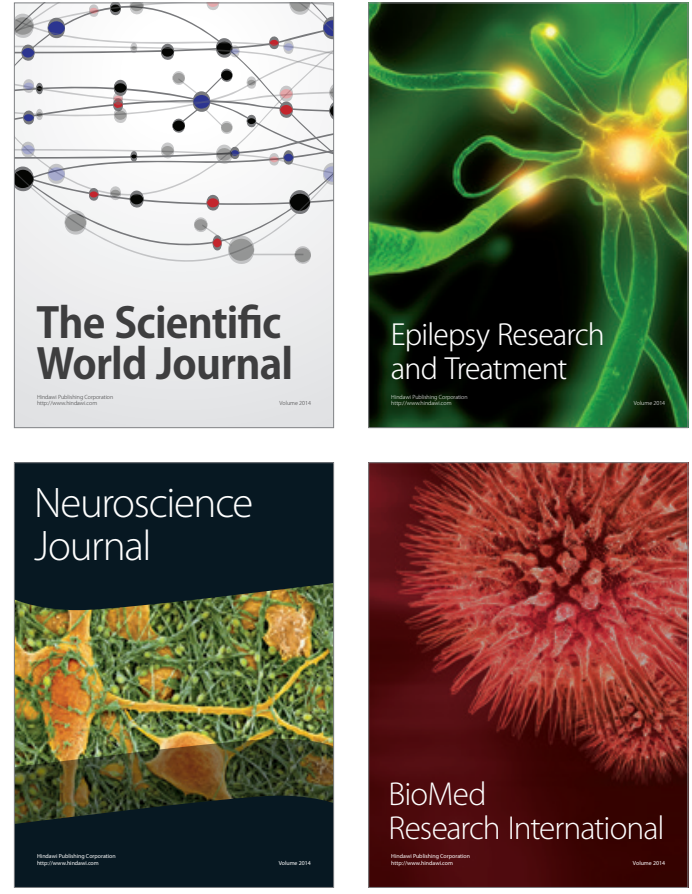

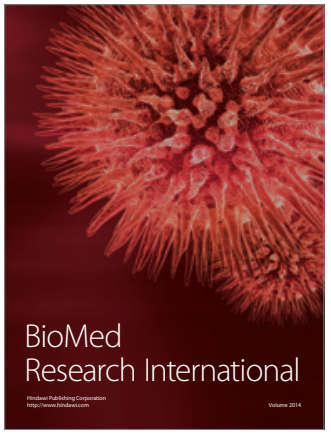

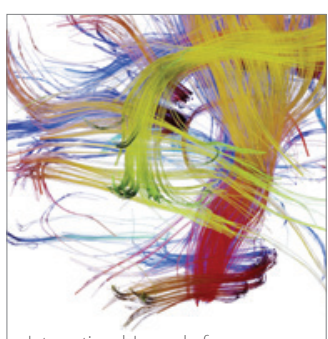

Brain Science

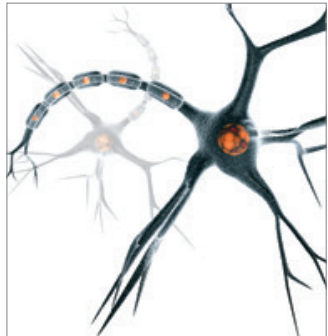

Neural Plasticity
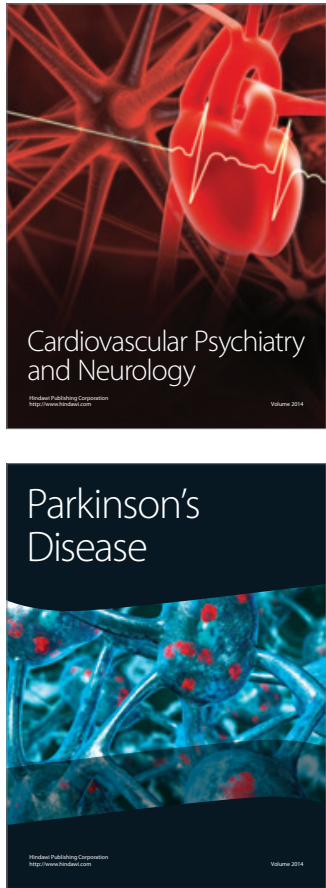